\section{New tool for checking epidural catheter location}

To the Editor:

It is with great interest that I read the case report by Patermann et al. describing the inadvertent intrathoracic placement of a thoracic epidural catheter inserted via a median approach. ${ }^{1}$ The authors of this article should be commended for a hasty and cautious response to this rare clinical situation. However, I do not agree with the authors' statement that, "the correct insertion of catheters into the epidural space can thereby only be verified by demonstrating a neural block". Although many consider radiological imaging to be impractical and cumbersome, this technique can clearly verify the position of an epidural catheter prior to the injection of local anesthetic. The newly introduced epidural stimulation test can also provide objective and practical information regarding epidural catheter location.

The use of electrical stimulation has shown to be a useful and reliable real-time technique to confirm epidural catheter placement. ${ }^{2,3}$ Not only do muscle twitches elicited by low current stimulation detail the position of the catheter in the epidural space, but the threshold current for motor response can also predict improper placement. ${ }^{4}$ When a catheter is situated properly within the epidural space, muscle twitches should be elicited with a current between 1 to $10 \mathrm{~mA}$. However, if any motor response is detected at a current less than $1 \mathrm{~mA}$ or greater than $10 \mathrm{~mA}$, improper placement should be suspected. The advantage of this real-time stimulation test is that improper catheter placement can be ruled out prior to the administration of a potentially harmful test dose and/or loading dose of local anesthetic. Although there is no reported case regarding how the epidural stimulation test would respond to a catheter situated in the intrapleural space, I suspect that this situation would elicit local muscle stimulation, similar to a catheter placed in the $s c$ tissue, ${ }^{5}$ rather than a typical epidural nerve root stimulation response.

However, it is important to point out that even if a confirmation test is utilized, the authors' statement, "rare complications should be kept in mind when performing a thoracic epidural anesthesia" still holds true. $^{1}$

Ban C.H. Tsui MD FRCPC

University of Alberta Hospitals, Edmonton, Canada E-mail: btsui@ualberta.ca

\section{References}

1 Patermann B, Lynch J, Schneider P, Weigand C, Kampe $S$. Intrathoracic positioning of a thoracic epidural catheter inserted via the median approach (Letter). Can J Anesth 2005; 52: 443-4.

2 Tsui BC, Gupta S, Finucane B. Confirmation of epidural catheter placement using nerve stimulation. Can J Anaesth 1998; 45: 640-4.

3 Tsui BC, Wagner A, Cave D, Kearney R. Thoracic and lumbar epidural analgesia via the caudal approach using electrical stimulation guidance in pediatric patients: a review of 289 patients. Anesthesiology 2004; 100: 683-9.

4 Tsui BC, Gupta S, Finucane B. Detection of subarachnoid and intravascular epidural catheter placement. Can J Anesth 1999; 46: 675-8.

5 Tsui BC, Guenther C, Emery D, Finucane B.

Determining epidural catheter location using nerve stimulation with radiological confirmation. Reg Anesth Pain Med 2000; 25: 306-9.

\section{Reply:}

Thank you for your interest in our report of the intrathoracic migration of an epidural catheter. Concerning the letter of Dr. Schricker, we would like to provide additional details of the presented case. The patient had a weight of $85 \mathrm{~kg}$ at a height of $152 \mathrm{~cm}$, which reflects a body mass index of 36.8. She had no respiratory, inflammatory or infectious diseases, and was not taking any medication.

The epidural space was identified by the loss-of-resistance technique using a 10-mL syringe filled with saline and a Tuoby needle. The volume of saline administered into the epidural space was about 5 to $7 \mathrm{~mL}$. No pain, dyspnea, shortness of breath, cough or shoulder pain were observed during puncture. During insertion of the catheter the patient complained momentarily of acute pain located in the area of insertion. The catheter inserted was a $G 18 \times 31 / 4$ " (Perifix $®$ Soft 520 Catheter, B. Braun, Melsungen, Germany) with a soft tip which is not armoured, nor equipped with a stylet. To exclude unrecognised intravascular or intraspinal catheter placement, a test dose of mepivacaine $2 \%$ with epinephrine $5 \mathrm{\mu g} \cdot \mathrm{mL}^{-1}$ was administered uneventfully after a negative aspiration test. I did not wait for the spread of sensory block. Eventually, the misplacement might have been recognized by a lack of typical sensory block, as pointed out in the discussion.

We appreciate the suggestion of Dr. Tsui using electrical stimulation to confirm epidural catheter placement, although we do not have any personal experience with this approach. We agree that this may be a helpful tool in identifying catheter misplacements. 
Britta Patermann MD

University of Cologne, Cologne, Germany

E-mail: bpatermann@web.de

\section{Vital capacity and patient-controlled sevoflurane induction}

To the Editor:

We read with interest the article by Yogendran et al. ${ }^{1}$ comparing patient controlled inhalation induction (PCI) with the most commonly used vital capacity induction (VCI). The authors concluded that "PCI was comparable to VCI in sevoflurane induction with respect to the speed of induction, side effects during induction and patient satisfaction".

We partially disagree with this conclusion because we believe that there was a problem with the VCI in the study. Considering that the volume of gas inhaled in a vital capacity inspiration is $70 \mathrm{~mL} \cdot \mathrm{kg}^{-1}(5.6 \mathrm{~L}$ for an 80 -kg patient) and requires a very high peak flow that current vaporizers cannot accommodate, and considering that the authors used a circle breathing system connected to a Datex-Ohmeda ${ }^{\circledR}$ AS/3 unit with a canister volume of $900 \mathrm{~mL}$ and a 2 -L reservoir (information obtained from authors), and assuming the average patient's weight is $80 \mathrm{~kg}$, the primed circuit afforded half of the volume needed for a VCI induction. Consequently, patients in the VCI group didn't breath sevoflurane 6 to $8 \%$, but instead received diluted sevoflurane 3 to $4 \%$ during the first minute of induction. This might explain the 1.5 -min necessary to achieve loss of eyelash reflex in the VCI group in the present study, in contrast to the induction times (32 to $54 \mathrm{sec}$ ) generally reported by other authors, ${ }^{2-4}$ even without $\mathrm{N}_{2} \mathrm{O} .{ }^{5}$ Five-litre reservoir bags should be used, and fresh gas flow can be reduced to $2 \mathrm{~L} \cdot \mathrm{min}^{-1}$ after loss of conciousness to diminish sevoflurane consumption in VCI.

Marie-José Colas MD FRCPC

René Martin MD FRCP

Centre Hospitalier Universitaire de Sherbrooke, Sherbrooke, Canada

E-mail: rene.martin@USherbrooke.ca

\section{References}

1 Yogendran S, Prabhu A, Henly A, et al. Vital capacity and patient controlled sevoflurane inhalation result in similar induction characteristics. Can J Anesth 2005; 52: 45-9.

2 Yurino $M$, Kimura $H$. A comparison of vital capacity breath and tidal breathing techniques for induction of anaesthesia with high sevoflurane concentrations in nitrous oxide and oxygen. Anaesthesia 1995; 50: 308-11.

3 Yurino $M$, Kimura $H$. Induction of anesthesia with sevoflurane, nitrous oxide, and oxygen: a comparison of spontaneous ventilation and vital capacity rapid inhalation induction (VCRII) techniques. Anesth Analg 1993; 76: 598-601.

4 Colas MJ, Tétrault JP, Dumais L, Truong P, Claprood $\Upsilon$, Martin $R$. The SiBI connector: a new medical device to facilitate preoxygenation and reduce waste anesthetic gases during inhaled induction with sevoflurane. Anesth Analg 2000; 91: 1555-9.

5 Yurino $M$, Kimura $H$. Comparaison of induction time and characteristics between sevoflurane and sevoflurane/nitrous oxide. Acta Anaesthesiol Scand 1995; 39: 356-8

\section{Intubating conditions associated with the Mallampati "class zero" airway}

To the Editor:

The recent correspondence by Sakuragi et al. describing tracheal intubation in an adult male with a Mallampati class zero airway was of interest to us. ${ }^{1}$ Although it was correctly identified that Ezri et al. failed to identify any adult men with a Mallampati class zero airway in a series of 764 patients, ${ }^{2}$ two such cases have been reported previously. 3,4

We, too, have encountered patients with a class zero airway. The first patient was a 48-yr-old male whose epiglottis was visible on mouth opening and tongue protrusion. Ventilation was easily managed following induction of general anesthesia. Cormack and Lehane laryngoscopy was grade 1 , and he was easily intubated. ${ }^{3}$ However, the experience from a limited number of cases does not imply that a Mallampati class zero airway will predict easy intubation, as suggested by Sakuragi et al. ${ }^{1}$ We have also reported a difficult grade 3 laryngoscopy in a 52 -yr-female with Mallampati class zero airway, due to a large obstructive epiglottis. ${ }^{5}$ However, we did not encounter difficulty in mask ventilation in this patient. In contrast, in a 69-yr-old male patient with a Mallampati class zero airway, Fang and Norris reported extreme difficulty in mask ventilation, in addition to difficult intubation with a laryngoscopic view grade $3 .{ }^{4}$ It is possible that a large redundant epiglottis acts as a flap, blocking the glottic opening every time positive pressure is applied to ventilate the patient. Further, a large epiglottis may 